\title{
THE EFFECT OF MICROELECTRONICS ON THE NATIONAL TELEPHONE NETWORK IN HUNGARY
}

\author{
ISTVÁN HÁZMAN \\ Research Institute of the Hungarian Post Office Budapest, Hungary
}

(Received April 16, 1981; in final form October 20, 1981)

\begin{abstract}
The paper deals with the general construction of the telephone network and the role of microelectronics in its development, and gives a short description of the extension of telephone services by the new equipment in rural areas in Hungary.
\end{abstract}

\section{THE WORLD TELEPHONE NETWORK}

Bell's telephone system has been formed by acoustoelectrical and electro-acoustical transducers i.e. the microphone and the earphone, hybrid transformers for direction coupling and a pair of wires, connecting the subscribers' sets together (Figure 1.) This simple arrangement has been quite suitable for conversations in spite of the energy-coupling between the mouth and the microphone being poor, with significant proportions of the electrical speech power getting lost in the hybrids and in the line, and the effectiveness of the re-transmission by the earphone also being poor. All of the above losses are balanced by the amplification of the carbon microphone that controls the electrical current of a battery and generates electrical speech power, many times higher than the acoustical power leaving the speaker's mouth. The distance between the parties can be many miles and the telephone circuit brings them very close to each other. While in face-to-face conversation the usual distance between speakers is 1 to 1.5 metres in the case of tele-conversation the optimum equivalent value is less than 1 metre, i.e. the earphone must provide somewhat more speech power, than that arrives to the ear of the listener in direct conversation, as the transmission impairments and the disturbing noises from the listener's surroundings diminish the intelligibility of the speech.

The application of switching exchanges, which was first suggested by Theodore Puskás, ${ }^{1}$ has made possible the evolution of telephone networks serving great numbers of subscribers; by using multi-stage switching, large and economical networks can be built. The only limiting factor has been the loss increasing with the growing distance to the farthest subscribers. A very useful tool for diminishing the attenuation of cables was the inductive loading proposed by Pupin. ${ }^{2}$ This method of augmenting the signal amplitude is widely used nowadays, because of its simplicity. In the simple two-wire system, i.e. when the same pair of wires is used for transmission in both directions, the amount of the electronic amplification is restricted by the potential instability. Only in the case of four-wire transmission, i.e. when one pair of wires serves for transmission in one direction and another pair for the other direction, is it possible to diminish the loss to zero without the danger of instability. The transmission lines are very expensive and for getting an economical solution it is necessary to use them in a multiplexed manner, i.e. the same line for many connections at the same time.

A suitable world network can be realized by using hardware as follows;-

- Bell's telephone set,

- two-wire and four-wire electromechanical switching exchanges,

- two-wire lines, mostly unamplified, possibly inductive loaded or amplified,

- four-wire multiplexed circuits with near zero loss.

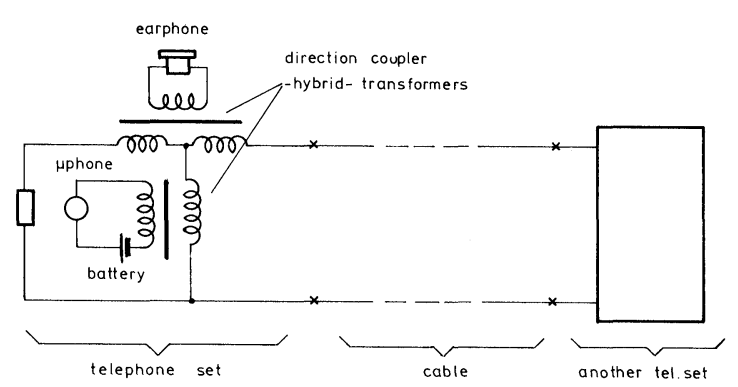

FIGURE 1 Diagram of acouso-electrical telephone system. 
The network consists of;-

i. local areas formed by certain group of subscribers located in the vicinity of the local exchanges. The local lines are used mostly by only one subscriber, hence they must be cheap; only two-wire lines and exchanges are economical here.

ii. national and international networks formed by four-wire multiplexed circuits of nominally zero loss and four-wire exchanges. (The exchanges where the circuits end are called primary exchanges or primary centres.)

iii. junctions between the local and the primary centres, formed mostly by two-wire loaded lines (Figure 2.).

\section{THE ROLE OF MICROELECTRONICS}

Recent development of the telephone network has been carried out invoking microelectronics. By using electronic circuits every kind of electrical signal can be processed in a variety of ways. Everywhere and in all cases, where and when it is possible to find proper transducers to translate the information into electrical signals or into memorizable electrical quantities, and vice versa, processing by microelectronic devices and instruments is the most productive and economical solution.

In telephony the transducers are available, and wellformed demands on the type of the service required are available, too. Consequently, the introduction of microelectronic equipment into networks can be carried out smoothly.

The requirements are complex. It is necessary to transmit the speech information in two directions, continuously, during the conversation. Totally different problems emerge during the building up of connections and during their continuous supervision. Moreover, only after adding the demand on

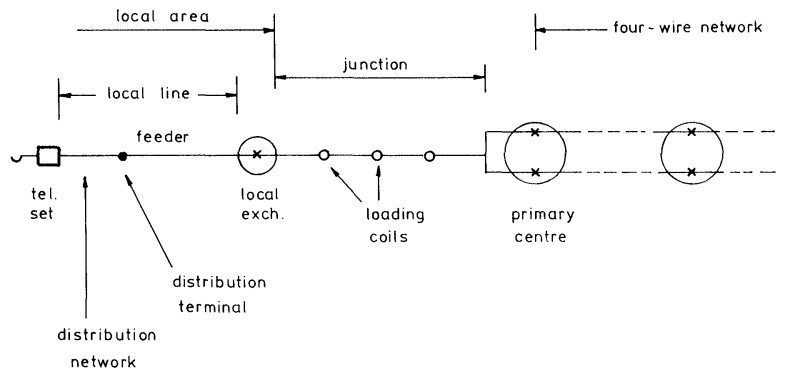

FIGURE 2 Connecting system between local and primary telephone centres. power supplies, overvoltage protection, maintenance and fault-detection, can the scope of the requirements be outlined.

It is widely known that digital techniques were the motive power for the rapid development of integrated electronics. ${ }^{3}$ Besides the wide range of the commercial digital integrated circuits, the advanced technologies of microelectronics have made possible the manufacturing of analogue circuits, as well, which can be as complex as whole racks of apparatuses were before. The realization of very complicated systems became possible and the situation is very different from that which existed ten years ago.

Without claiming completeness, it is worth examining some apparatus required.

\section{a. Analogue Solutions:}

i. Analogue integrated circuits have helped to re-construct the subscriber's set ${ }^{4,5}$ :

- In the place of the carbon microphone a high-quality and low-distortion transducer can be used, together with an integrated amplifier.

- Instead of the hybrid transformer, electronic direction coupler and amplifiers can be used.

- A push-button operated electronics signalsender can be built-in for dialling.

- A loudspeaker can be used for ringing, instead of a bell.

ii. In the transmission ${ }^{6}$ the effect of analogue microcircuits has been modest; however, in the circuitry of the frequency-division-multiplex systems the multiplying modulator, demodulator, phaselocking-loop and active RC-filter microcircuits are widely used. ${ }^{7}$ The integrated compandor ${ }^{8}$ is a device that has made possible the development of cheap small-channel FDM systems for extended applications in local and junction cables.

iii. For the exchanges many analogue switching devices have been developed - with limited applications. Most of the electronics analogue exchanges work by reed relays, a mechanical switch, the reliability of which can be higher than that of simple electromechanical contacts. Nevertheless, all other functions of modern exchanges have electronic solutions, usually in digital form. ${ }^{9}$

\section{b. Digital Solutions:}

i. The digital transmission systems use pulse-codemodulated multiplex (PCM) apparatus. ${ }^{10}$ These give four-wire connections. The role of FDM modulators 
and demodulators has been taken over by encoders and decoders. The present system converts the analogue speech signal into a stream of digital impulses that can be transmitted with little distortion on lines of unlimited length by using regenerators at certain distances. At the output of the decoder a nearly undistorted speech signal can be obtained. A great number of signals can be transmitted simultaneously on the same path, using time division multiplexing, rather than the multifrequency solution of the FDM systems.

ii. The full advantages of digital transmission techniques can be obtained only by using digital techniques for switching, as well. With the development of electronic digital exchanges, compatible with PCM transmission systems, an homogeneous integrated digital telephone network can be formed, showing the same improved quality of parameters, regardless of size. ${ }^{11}$

iii. Digital transmission can be extended to the subscriber. ${ }^{12}$ In this case the coder is placed in the telephone set, and the transmission between the microphone and the earphone is purely four-wire type. There is no danger of electrical instability and unwanted echoes, and optimum amlification can be used.

Digital telephone equipment needs large-scale integrated circuits; most of them are applicationsoriented, custom-designed. ${ }^{3}$ In addition, partly analogue and partly digital circuits are used, e.g. the coder, regenerator, subscriber line interface, etc.

Several years ago, progress in computer technology made it possible to build computer-controlled exchanges. The stored program control (SPC) ${ }^{13}$ can be included in every kind of exchange and helps to augment the quality of services and to make the most of the switching equipment. The maintenance and fault detection can be automated, as well. Both analogue and digital electronic exchanges can be computer-controlled and SPC service can be installed even in electromechanical exchanges for diminishing the facility gap between the subscribers connected by advanced and conventional exchanges, during the transition period when the two systems must work together.

\section{DEVELOPMENTS IN RURAL AREAS}

Some electronics telephone systems have been manufactured for several years but others are still in the experimental phase - or on the engineers' drawing board.
The investors' position is not too easy. They are under the influence of different interests.

First of all, the subscribers are not interested in the technological level of the equipment. Their need is a perfect service, no less and no more. Secondly, the traditional equipment can do the job properly and the personnel has got used to it. On the other hand, the new equipment is very attractive, makes the job easier and better than the old one and opens the gate for new services.

It is the task of the Administration to select the proper hardware - and software - that gives optimum solutions for the real demands.

Let's try to compare the advantages with the disadvantages of the new generation equipment!

It seems to be disadvantageous, as

- the new electronics systems are more expensive, especially just after their introduction,

- there is no immediate need for the new services of the new system,

- in living networks the technological homogenity ceases and a long period of coexistence for the 'old' and 'new' begins,

- the level of the services becomes different for the different groups of subscribers,

- highly educated personnel is needed.

The main advantages are as follows,

- shorter investment time, time,

- saving in the size of buildings and in the assembly

- fewer personnel are needed,

- the new equipment provides an overall better service for the subscribers,

- and provides the Administration with simpler maintenance and precise fault detection.

The use of new techniques in the construction of a telephone network, for instance, in the rural areas of Hungary will be used as an example.

In that country the number of primary centres is about 140, all of which are automatic, four-wire exchanges. Their surrounding network contains a local area in the town where the primary exchange is located and on average about six further local areas in the neighbourhood. Most of the distant/local exchanges are manual. The average area covered by a primary centre is about $600 \mathrm{~km}^{2}$, in which about 50000 inhabitants live.

Counting 27 telephone connections for 100 inhabitants, as an average for the whole country, the 

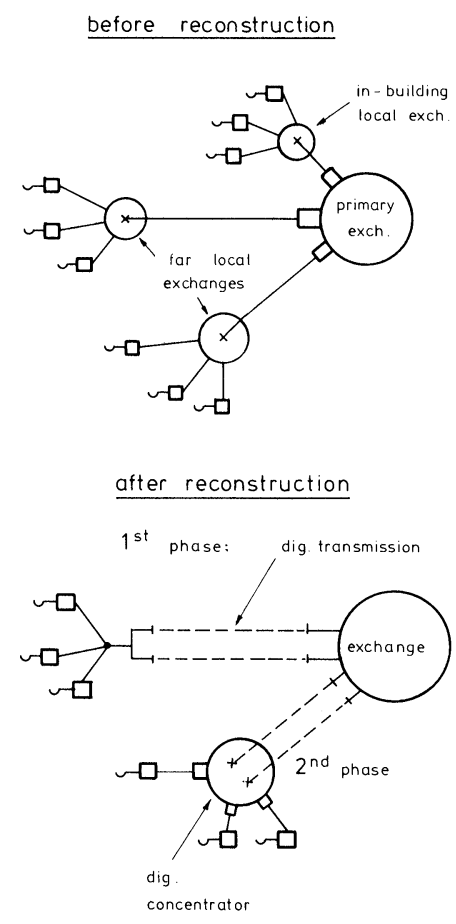

FIGURE 3 Reconstruction of telephone system using electronic equipment.

real demand in a rural area is about 5000 subscribers.

After examination it became evident that it is cheaper to eliminate the distant local exchanges and connect all of the subscribers directly to a single four-wire switching exchange, mostly by PCM transmission systems. ${ }^{14,15}$ At present, the systems end in distribution terminals and each channel serves only one subscriber. In the future, traffic-concentrator terminals will be placed at the distribution points. ${ }^{16,17}$

Thus we are taking advantage of a cheaper big exchange, and there is no need for new buildings. The new network can be built up continuously, step by step. A high level of service can be assured to all subscribers within a very short time. The investment time can be 2-3 years, instead of the usual 6-7 years, as only some renewal of the existing buildings is needed. It is necessary to consider and install some new aerials and regenerators. The electronic equipment used arrives from the factory in such a form that it needs very few adjustments in situ (Figure 3). ${ }^{18}$

\section{CONCLUSIONS}

Microelectronic circuits are widely used in the recently developed equipment for telephone networks.
Both analogue and digital solutions can be found. The analogue technique usually results in cheaper equipment, than the digital one; nevertheless, the long-range benefits of digitalisation make economical the step-by-step building up of the integrated digital telephone networks in sparsely populated rural areas of Hungary, as well.

\section{ACKNOWLEDGEMENTS}

I would like to thank my colleagues for their kind permission to publish some results of their studies. ${ }^{14}$

\section{REFERENCES}

1. Handscript of T.A. Edison on a photograph in the collection of the Museum of Hungarian Post Office.

2. D.L. Ritchards, Telecommunication by speech: the transmission performance of telephone networks. London. Butterworths, 1973.

3. C.E. White, Dominance in the semiconductor market a threat to have-nots. Telecommunication, 14. 19-20. Aug. 1980.

4. SGS adopts systems approach to all electronic telephone. Planar News, 3. 1. 16 March 1980.

5. Double chip dialling system interfaces directly within line. Planar News, 3. 4-5. 16 March 1980.

6. T.N. Rao, Analog loop carrier systems. BSTJ, 57. 1109-1128. Apr. 1978.

7. S. Browne, Inside the 13-channel SSB station carrier. Telecommunications, 11. 4. 55-60. April 1977.

8. C.C. Todd, A monolitic analog compandor. IEEE Journal of Solid-State Circuits, SC-11. 6. 754-762. Dec. 1976.

9. J.V. Goodman, J.L. Phillips, TXE4 electronic exchange system, part 1.POEEJ, 68. 196-203. Jan. 1976.

10. K.W. Cattermole, Principles of pulse code modulation. Iliffe, 1969

11. M. Tyler, J. Yeomans, Prospects for system X. Telecommunications, 13. 7. 20R-20T, 100A, 115-1. Aug. 1979.

12. J.E. Flood, Digital transmission on subscriber lines. Seminar on Digital Telephone Networks, Budapest, 1980

13. A.H. Bianchi, SPC features for electromechanical exchanges. Telecommunications, 14. 18G-18P. Aug. 1980.

14. G. Ecsedi, J. Darnóczy, A. Földes, S. Gránásy, Gy. Sallai, K. Tarnay, Technical and economical advantages of electronics in telecommunications. (in Hungarian) Posta Kisérleti Intézet, 1978.

15. Plessey Transmission systems. Rural Systems. Sept. 1979

16. W.L.G. Koontz, Economic evaluation of subscriber pair gain system applications. BSTJ, 57. 825-848. Apr. 1978.

17. N.G. Avaneas, J.M. Brown, The loop switching system. BSTJ, 57. 1157-1184. Apr. 1978.

18. T.J. Morgan, Economy and digital network planning. Seminar on Digital Telephone Networks, Budapest, 1980. 

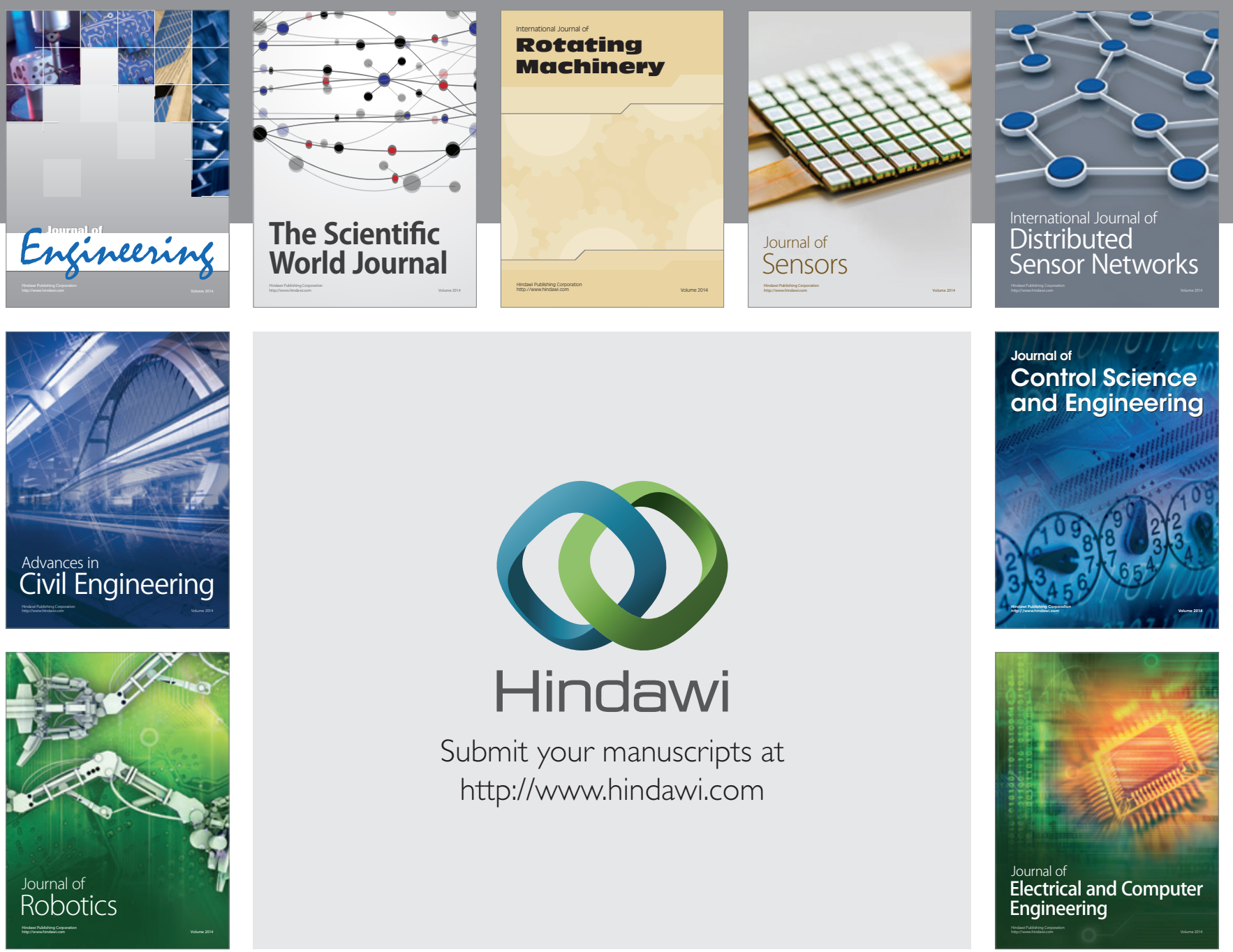

Submit your manuscripts at

http://www.hindawi.com
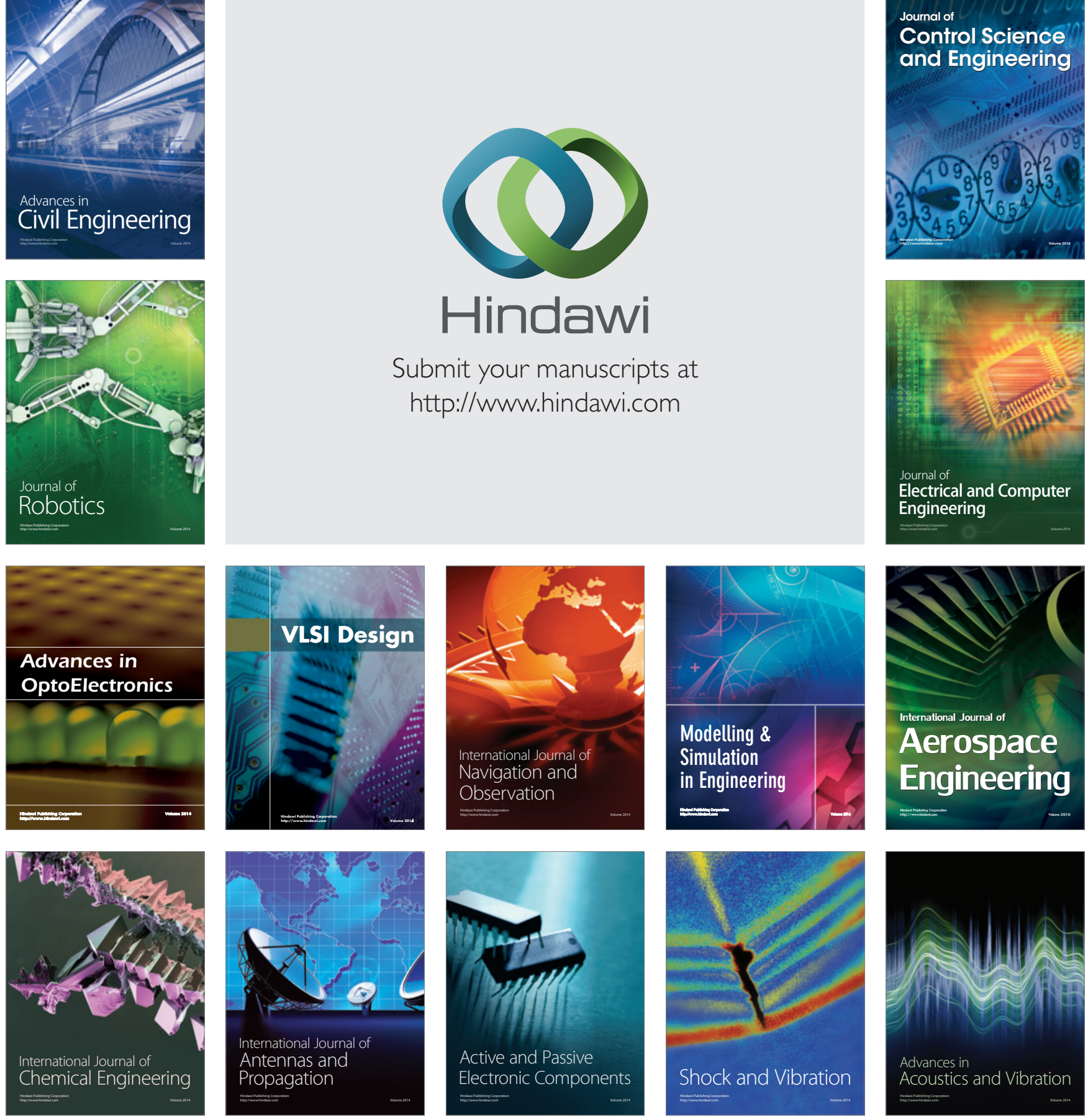